\title{
Camel mastitis: a review
}

\section{Summary}

Camel milk has high mineral contents of $\mathrm{Ca}, \mathrm{Na}, \mathrm{Mg}, \mathrm{Fe}$ and $\mathrm{Cu}$, low sugar and lower cholesterol and very high Vitamin C. Mastitis in camels has been reported from almost all camel rearing countries. Besides causing the loss in milk production, it has hazardous effects on human beings and suckling calves. Many infective agents have been implicated as causes of mastitis in camels, however, bacterial infections are considered the primary cause of mastitis in camel. Transmission mechanisms depend on the bulk of the infection in the environment, including: infected quarters; efficiency of milking personnel; susceptibility of the camel, which is related to the stage of lactation, age of the camel and level of inherited resistance. Subclinical mastitis is more prevalent than other form of mastitis, and unfortunately the affected animal could affect other animals because it acts as microorganism reservoir. Diagnosis of mastitis can be done through clinical examination, $\mathrm{pH}$ test, California Mastitis test, Somatic Cell Count, and bacteriological analyses for confirmation may be made by culturing. The prevalence of mastitis differs markedly due to geographical area and individual herd management. For instance, an overall prevalence of camel mastitis was found to be $30.2 \%$ and $76 \%$ in Eastern Ethiopia. Therapeutic approach in treating acute mastitis is via systemic antibiotics and anti-inflammatory drugs, with regular stripping of the mammary glands. Treatment of chronic mastitis is very difficult and the condition often results in the loss of the affected quarter. There are three main principles of mastitis control methods, such as elimination of existing infection, prevention of new infection and monitoring udder health status. Economic importance of mastitis includes: loss of milk production and quality with less favorable features, reduction in milk price due to high SCC presence, milk loss because of antibiotic treatment, and veterinary care costs. Therefore, targeting prevention and control effort is needed through early diagnosis, treatment and by avoiding possible risk factors.

Keywords: mastitis, camel, clinical mastitis, subclinical mastitis, risk factor
Volume 2 Issue 5 - 2017

\section{Kula Jilo,Wako Galgalo,Wario Mata}

School of Veterinary Medicine, College of Agriculture and

Veterinary, Ethiopia

Correspondence: Kula Jilo, School of Veterinary Medicine, College of Agriculture and Veterinary, Jimma Universiry, Ethiopia, Email kula.jilol@gmail.com

Received: June 14, 2017| Published: July 24, 2017

\section{Introduction}

\section{Background}

The camel (Camelus dromedaries or one humped camel) is the most dominant and widely distributed animal in the tropical and subtropical continents of Africa and Asia. It makes an important contribution to human survival and utilization of these in dry and arid land. ${ }^{1}$ They are considered as wealth investment and insurance against natural disasters that usually occur in the desert and lead to livestock mortality. Camels represent high significance in the lives of people living in the desert and protecting them and their products from mastitis is the most challenging task they are facing. ${ }^{2}$ Camel milk is one of the main components of diet of the nomads in semiarid and arid zones and is an essential food for livelihood of people and it may be the only milk available in places where other milking animals cannot be maintained. ${ }^{3}$ Camel milk also has valuable nutritional properties as it contains a high proportion of antibacterial substances and higher concentration of vitamin $\mathrm{C}$ in comparison with cow milk. ${ }^{4}$ Milk can be considered as a good source of minerals, vitamins and characterized by higher ratio of lactoferrin. Moreover, camel milk could meet a big part of the daily needs of humans from these nutrients because camel milk has most the essential nutrients. ${ }^{5}$ Camel milk has higher mineral contents including $\mathrm{Ca}, \mathrm{Na}, \mathrm{Mg}, \mathrm{Fe}$ and $\mathrm{Cu}$, low sugar and $40 \%$ lower cholesterol than that of cow milk. Camel milk contains about 2-3 times more Vitamin-C than cow milk. This Vitamin-C is of paramount importance for human diet in arid and semi-arid areas where fruits and vegetables are scarce or not available. It also increases the shelf life of milk by increasing the acidity. Camel is proving to be a good source of milk in India. Camel continues lactating even under stress conditions like drought, when the production of other milk animals' ceases. In camels the lactation length is longer and they may yield 5-6 liter of milk per day even during drought. ince of the increasing desertification and recurrence of drought and famine in sub-Saharan Africa, particularly in East Africa, the camel plays a very significant role as a source of milk, meat and draft power. In Ethiopia camels are kept in the arid and semiarid lowlands of Borena, Ogaden and Afar regions, which cover $50 \%$ of the pastoralist areas in the country. ${ }^{6}$ Mastitis is amajor complex disease occurring worldwide among dairy animals with heavy economic losses. Camel mastitis has been estimated to affect more than $25 \%$ of lactating she-camel. ${ }^{7,8}$ It is also known to cause approximately $70 \%$ losses in milk production. ${ }^{9}$

Mastitis has both an extreme zoonotic and economic importance. It is the cause of multiple hazardous effects on human health and animal production. ${ }^{10,11}$ Compared to bovine mastitis, few published information is available about the etiological agents associated with camel mastitis. Bacterial infections are considered the primary cause of mastitis in domestic animals. Some studies indicate that Staphylococcus aureus, streptococcus spp., ${ }^{12,13}$ Micrococcus spp. ${ }^{12}$ Streptococcus agalactiae, ${ }^{13}$ coagulase negative staphylococci, ${ }^{14}$ Staphylococcus epidermides, Pasteurella haemolytica and Escherichia coli $^{14,12}$ and Corynebacterium $s p p^{15}$ have been implicated as causes of mastitis in camels. Therefore, the aim of this review is to show the current status of Camel mastitis; its causes, mode of transmission, diagnostic methods, the prevalence, economic importance, treatment, prevention and control measures in place. 


\section{Objective of the seminar}

\section{General objective}

a. To review of an over view of Camel Mastitis

\section{Specific objective}

a. To identify the cause of camel mastitis

b. To review Economic Importance of Camel mastitis

\section{Literature review}

\section{Mastitis}

Mastitis can be defined as inflammation of the mammary gland regardless of the cause and is characterized by physical, chemical and, usually, bacteriological changes in the milk. It is also characterized by pathological changes in the glandular tissue. The most important changes in the milk include: discoloration, presence of milk clots and presence of a large number of leucocytes. ${ }^{16}$ While clinical cases are easy to detect by manual palpation and by visual examination of the milk using a strip cup (there is swelling, heat, pain and in duration in the mammary gland, and the milk is discolored and clotted), a large proportion of mastitis cases are not readily detectable; such cases are referred to as subclinical mastitis. In the latter cases, the diagnosis has become dependent largely on indirect tests which depend in turn on the leucocyte content of the milk. ${ }^{17}$ Mastitis is a relatively infrequent disease in camels compared with cattle, but the incidence of mastitis may increase in dairy camels due to hand milking and teat malformation. ${ }^{18}$ Acute mastitis has been reported to occur during the first few days following parturition, dystocia or cesarean section in the dromedary. ${ }^{19}$ Mammary secretions in these cases are watery, yellowish or blood-tinged and bacteria isolated have included Klebsiella pneumoniae and Escherichia coli. ${ }^{20}$ Milk from mastitis female is common source of infection for the newborn calf. Subclinical or chronic mastitis is suspected when the young fail to grow normally and when an anomaly of the conformation of the udder is observed, such as atrophy of one or more quarters, asymmetry or presence of pustules on the surface.

There are two types of mastitis; the first is contagious, and the second is environmental. Contagious mastitis is caused by Staphylococcus aureus, Streptococcus agalactiae and uberis. These pathogens usually located at the inside of the udders or on its skin. They spread through infected milk splashes and sprays while stripping, milk cross flow between tea cups, the hands of the person milking the animal. Environmental mastitis is caused by bacteria living in soil, bedding, water, manure, calving pads. Examples of these bacteria include Streptococcus uberis, Streptococcus dysgalactiae, Coliforms such as E. coli and Klebsiella, while the first can sometimes persist and spread though the milking process, the second does not survive in the udder and does not persist. ${ }^{21}$

\section{Camels in the Horn African and Middle East}

Camel is one of the most important animals of the Arab countries and it is deeply imbedded in their culture to the degree you can find more than 160 words that identify camels in the Arabic language. The number of camels around the world is about 11.24 million, and $61 \%$ of them are located in the Arab countries, while the remaining is distributed across the rest of the world. In the Arab world, they are important producers of meat, milk, and wool $(9 \%, 24 \%$, and $8 \%$, respectively). In Saudi Arabia, camel meat constitutes about 30\% of the total, and it is considered a source of wealth and investment to individuals still located in the desert parts of the country. Saudi Arabia contains about 600,000 camel head; as any other animal they are threatened by various diseases..$^{22,23}$ This is also true for many other desert or semi-desert Middle Eastern counties as well as the African horn countries, where camels are used for transportation, racing competition, and investment. The main type is dromedary camles (Camelus dromedarius), they are the most important livestock animal. Because of the difficult climate and constant changes, only camels can survive and adapt to these changes while other livestock is lost dramatically. That's why, camels are essential for humans in these areas. ${ }^{24}$ One of the largest countries of the African horn is Sudan, and they have the largest animal population among Arab counties and second largest among African countries. For camel population, it is considered the second largest country containing camels they have about 4 million camel head and constitute $22 \%$ of Sudan animal population, and $26.3 \%$ of Arab camel population. Sudan contains many well-known Arabic trips which depend on camels for their life style, because camel herds are insurance when living in the desert against natural disasters. ${ }^{25}$

For these countries, camels are important not only for milk production but also for the husbandry system. Camels have been identified as source of milk and meat with the increased human population in the developing countries. For these desert countries, camels are the best animals to sustain the hard situation of the desert such as heat, and water and food scarcity. Camels have advantage over other cattle in their ability to provide sustained average milk production over the year. Also, camel's milk is more nutritious than other types due the high presence of proteins, fats, vitamins, and minerals. Another advantage of the camel milk is its medicinal characteristics and helps cure some diseases such as; jaundice, asthma, anemia, food allergies, dropsy, spleen diseases and piles. ${ }^{26}$ Continuous care and attention to improve the breeds of the camels and their health as well will ultimately conserve their value and increase it as source of meat and milk. That's why, camel disease raises many concerns in order to fight and overcome them as much as possible to avoid losing this industry. Originally, camels were thought to be immune against most diseases which usually affect other livestock, but it was found out that they are subject to large group of microorganisms that could threaten calves live. ${ }^{27}$

\section{Causes of camel mastitis}

Many infective agents have been implicated as causes of mastitis in camels, the commonest being bacterial infection. The documented common causes of bacterial mastitis in camels are Streptococcus, Staphylococcus, Micrococcus and Aerobacter species and Escherichia coli in that descending order of importance ${ }^{28}$ Streptococcus agalactiae and Staphylococcus aureus have been documented as the two most important mastitis pathogens in camels. Many different bacteria have been isolated from mastitic mammary glands in camels either in the form of pure or mixed infection ${ }^{29,30,8}$ There are various studies which have been conducted worldwide on the isolation and identification of bacterial organisms in mastitic camel milk and their effect on quantity and quality of milk. Acute or chronic mastitis is one of the important diseases of she-camel in Eastern Sudan. The isolates Staphylococcus aureus, Escherichia coli, Corynebacterium spp. are the main causes of mastitis in camels (Table 1). ${ }^{31-33}$

\section{Transmission}

Transmission mechanisms depend on the bulk of the infection in the environment, including: infected quarters; efficiency of milking personnel; susceptibility of the animal/camel, which is related to the 
stage of lactation, age of the camel (older animals more susceptible) and level of inherited resistance (possibly related to teat shape and anatomy of the teat canal); lesions on the teat skin especially the orifice; and the immunological status of each mammary gland (Figure 1). ${ }^{34}$

Table I Mastitis pathogens isolated from camels with clinical and subclinical mastitis

\begin{tabular}{llll}
\hline \multirow{2}{*}{ Mastitis pathogen } & \multicolumn{2}{l}{ Num. of cases } & Total \\
\cline { 2 - 3 } & $\begin{array}{l}\text { Clinical } \\
\text { mastitis }\end{array}$ & $\begin{array}{l}\text { Subclinical } \\
\text { mastitis }\end{array}$ & \\
\hline Staphylococcus aureus & 2 & 171 & $173(21.1)$ \\
Staph. Hyicus & 1 & 206 & $207(25.3)$ \\
Streptococcus dysgalactiae & - & 28 & $28(3.4)$ \\
Streptococcus agalactiae & 2 & 24 & $26(3.2)$ \\
Enterococcus faecalis & - & 18 & $18(2.2)$ \\
Sirept uberis & - & 7 & $7(0.9)$ \\
Streptococcus uberis & - & 86 & $86(10.5)$ \\
Staph. intermedius & - & 67 & $67(8.2)$ \\
Staph. epiderrnidis & - & 81 & $81(9.9)$ \\
Corynebacterium ulcerans & - & 15 & $15(1.8)$ \\
Corynebacterium bovis & - & 13 & $13(1.6)$ \\
Actinomyces pyogenes & - & 5 & $5(0.6)$ \\
Escherichia coli & - & 3 & $3(0.4)$ \\
Pasteurella haemolytica & - & 1 & $1(0.1)$ \\
Bacillus spp. & - & 88 & $88(10.8)$ \\
Total & 5 & 813 & 818 \\
\hline
\end{tabular}

Source: witubit et al., 2001

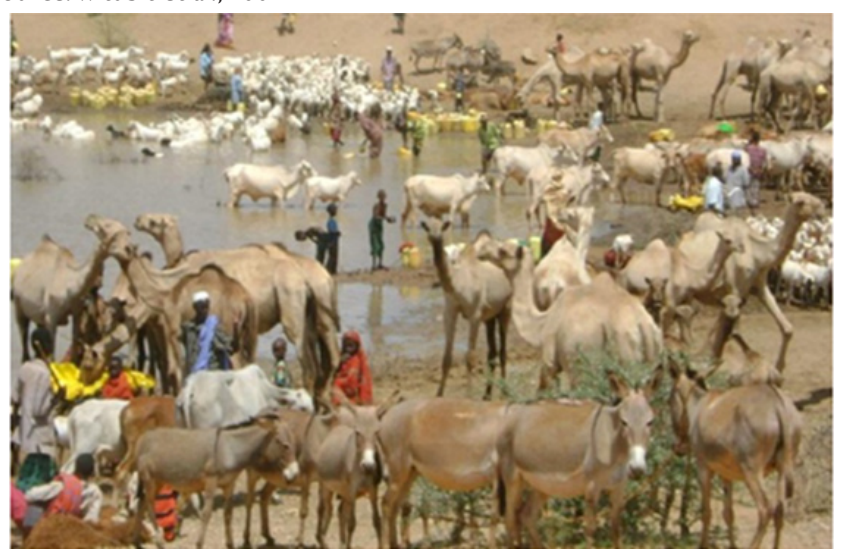

Figure I Interaction of Camels with different species of animal at watering point. $^{62}$

\section{Clinical signs and diagnosis}

Mammary infections result in milk compositional changes such as increase in leukocyte counts, leakage of plasma proteins into the milk and cell damage, resulting in leakage of intracellular constituents into milk, change in ion composition and decrease in milk production..$^{35}$ Inflammation severity is divided into; clinical, subclinical, and the rare form of chronic mastitis. The degree of inflammation of each type depends on many factors such as; pathogen nature, animal's breed, animal age, and animal health and immunity status. ${ }^{25}$ Clinical mastitis is characterized by anorexia, fever, general depression, swelling, severe inflammation and pain of the udder (Plates 2-1 and 2-2), which can cause rejection of the newborn by the female. ${ }^{36}$ Clinical mastitis is self-evident and can be detected without special test. ${ }^{3}$ There are changes in the secreted milk (color, consistency, floccules etc) and/or the udder (red, swollen) and other generalized signs exhibited by the animal (fever, anorexia, deteriorating body condition).

Subclinical mastitis, on the other hand, is difficult to diagnose and depends on various test procedures aimed at detecting the cause or products of inflammation in milk (IDF, 1987). A camel with subclinical mastitis produces less milk, but does not have a swollen udder or abnormal milk. Infection is present but can only be detected with the help of indirect methods ${ }^{37}$ These include the California mastitis test (CMT), and Direct microscopic somatic cell count (DMSCC) a simple and rapid test that can be applied in the field; it is particularly used to detect subclinical udder infections caused by either one of the two major mastitis pathogens: Streptococcus agalactiae and Staphylococcus aureus. The direct microscopic somatic cell count (DMSCC), which requires only simple laboratory equipment and produces results on the same day. However, there has been a problem in interpretation of results of these tests because the basal levels of cells and their physiological variations in the camel are still not yet established (Figure 2)..$^{38}$

Symptoms and signs differ according to the type of mastitis wither it is clinical, subclinical, or even chronic. Also, in each type the severity of the disease and the causative pathogen will control the observable symptoms. Clinical mastitis could be diagnosed as mild (sub-acute) when the disease symptoms are restricted only to minor alteration of the milk with presence of clots and flakes in the affected quarter, and if the secreted milk was discolored, and slight swollen and tenderness of the quarter. Clinical mastitis could be diagnosed as acute when there is a sudden onset, presence of heat, swelling, pain, redness, along with reduced and changed milk production, also there could be accompanying fever, weakness, and depression. Sever clinical mastitis could be fatal for the animal so immediate intervention is necessary. Subclinical mastitis is undetected usually because its symptoms are less visible, and it is diagnosed only though testing the Somatic Cell Count (SCC) of the milk. SCC increase in the presence of injury and inflammation. This type is important because it usually precedes the clinical form for a long period of time and it is difficult to detect it, and it affects both the milk's quality and quantity. Subclinical mastitis is more prevalent than the clinical form, and unfortunately the affected animal could affect other animals because it acts as microorganism reservoir (Figure 3 ) ${ }^{39}$ In the diagnosis and control of mastitis in camels, laboratory procedures are of value in the examination of milk samples for cellular, bacterial and chemical changes. Much attention has been given to the development of field tests based on physical and chemical changes in milk. ${ }^{15,40}$ These tests are indirect and detect only presence of inflammatory changes; they are of value only as screening tests and may need to be supplemented by bacteriological examination for determination of the causative organism..$^{18,40,41}$ The physical tests carried out on milk in a mastitis examination are limited to the cell count and its immediate development; it is normally a bulk milk cell count. Indirect tests are also limited entirely to tests such as the California mastitis test (CMT) and the white slide test which are dependent on the cell count. Other indirect tests are the chloride content test, electrical conductivity test and test for camel serum albumin ${ }^{37}$ The latter tests are more accurately diagnostic of damage to mammary epithelium as in bovine mastitis. Since present day emphasis in mastitis control is on maintaining a particular programme of hygiene and continuous monitoring of subclinical mastitis, clinico-pathological tests are the best choice they are practical for quick screening. 


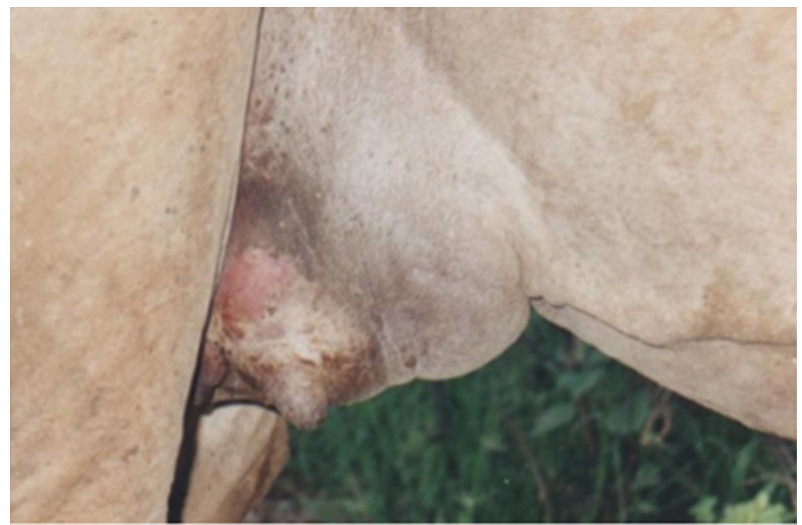

Figure 2 Clinical mastitis. ${ }^{62}$

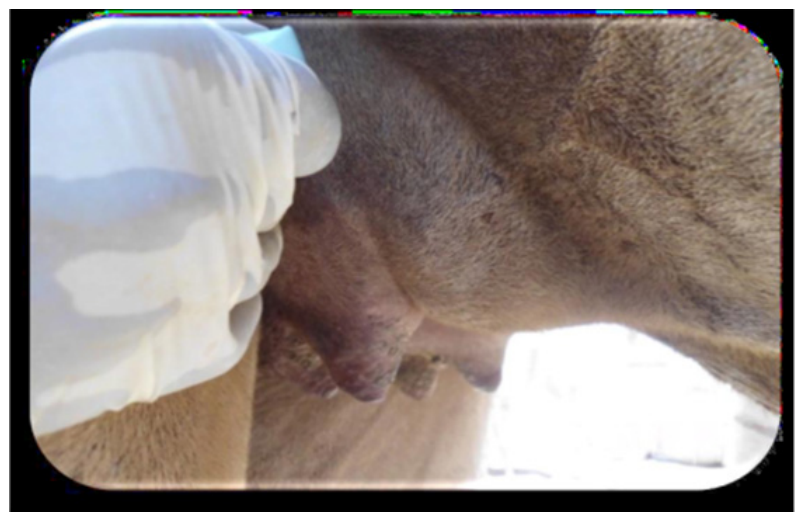

Figure $3 \mathrm{~A}$ case of acute mastitis. ${ }^{23}$

\section{Physical examination of udder and milk}

Udder abnormalities such as swelling, presence of lesions or anatomical malformations must be examined. The size of the rear and forequarters, indurations and fibrosis should be examined by deep digital palpation. The milk can be examined for its consistency, color and other visible abnormalities. Clinical mastitis may have recognized by abnormal milk, signs of udder infection and detection of mastitis pathogens by bacteriological culture, whereas subclinical mastitis can have recognized by apparently normal milk and an increase in leukocyte counts as evidenced by CMT and a positive culture result (Figure 4).

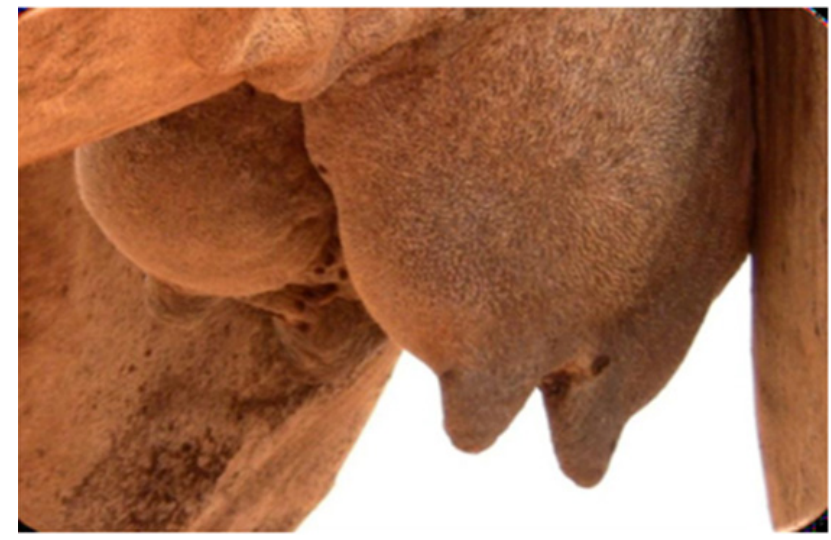

Figure $4 \mathrm{~A}$ case of chronic mastitis. ${ }^{23}$

\section{$\mathrm{pH}$ reaction of milk}

Hydrogen ion concentration of milk was determined immediately after milking using digital $\mathrm{pH}$ meter. Normal camel milk $\mathrm{pH}$ is approx. 6.2, if this increases to 6.4 or more is indicative of sub clinical mastitis.

\section{California mastitis test (CMT)}

It measures indirectly the SCC score in milk samples. It uses a bromocresol-purple-containing detergent to break down somatic cell membrane to release nucleic acid and aggregate it to form a gellike matrix in which its viscosity is proportional to the leukocyte number. ${ }^{41}$ SCC is carried out to establish the relationship between the udder infection and the number of cells in camel milk. The direct microscopic somatic cell count (DMSCC) method as described by $^{42}$ can be also used. Sub-clinical mastitis was diagnosed based on CMT results and the nature of coagulation and viscosity of the mixture (milk and CMT), which show the presence and severity of the infection, respectively. rading of the test is based on the number of SCC in milk, since breakage of cell leads to gel formation which is easy tool to interpret. Plastic paddle having four shallow cups is used. Equal amount $(3 \mathrm{ml})$ of milk and the reagent are put into each cup of the paddle and the contents are mixed by a gentle circular motion of the paddle in a horizontal plane. The interpretation of the test was as follows: CMT score 0 was taken as "negative" (-ve), while CMT scores "Trace," -positive one (1+), -Positive two (2+) and -positive three $(3+)$ were considered positive (Table 2) (Figure 5).

Table 2 Classic grading and interpretation of CMT score

\begin{tabular}{|c|c|c|}
\hline Score & $\begin{array}{l}\text { Suggested } \\
\text { meaning }\end{array}$ & Description of visible reaction \\
\hline- & No reaction & Mixture remains liquid \\
\hline $\mathrm{T}$ & Trace & $\begin{array}{l}\text { A slight slime with no tendency towards gel } \\
\text { formation. }\end{array}$ \\
\hline+ & Weak & $\begin{array}{l}\text { A distinct slime with no tendency towards } \\
\text { gel formation. }\end{array}$ \\
\hline++ & Distinct + ve & $\begin{array}{l}\text { Mixture thickens immediately with gel } \\
\text { formation. On continued swirling, mass } \\
\text { moves around the periphery leaving the } \\
\text { bottom of the cup exposed. }\end{array}$ \\
\hline+++ & Strong +ve & $\begin{array}{l}\text { A distinct gel forms, which tends to adhere } \\
\text { to the bottom of the paddle and during } \\
\text { swirling a distinct central peak is formed. }\end{array}$ \\
\hline
\end{tabular}

Source: ljaket aL, 2013.

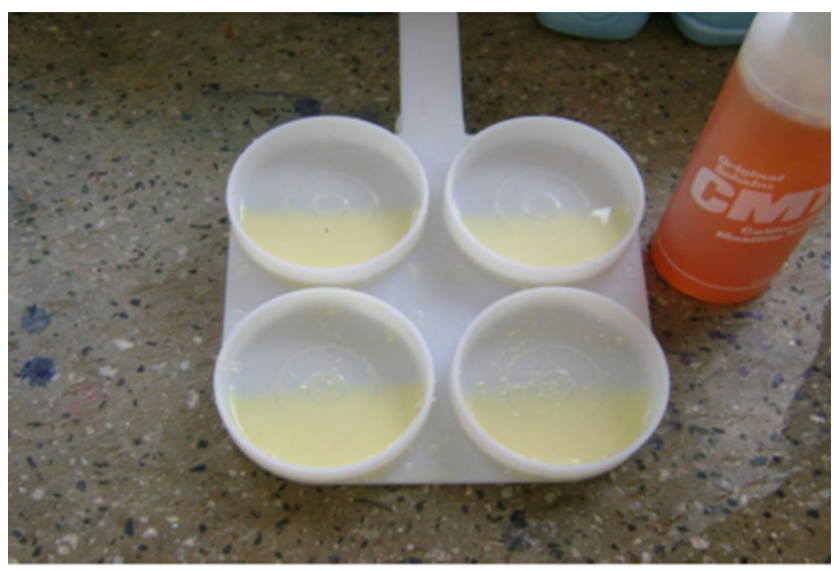

Figure 5 California mastitis test reaction. ${ }^{23}$ 


\section{Bacteriological analyses}

Isolation and identification of microorganisms should be done in Microbiology Laboratory. Bacterial isolation and identification must be done according to standard procedures. A loop full of milk sample should streaked onto a plate of blood agar, MacConkey agar or other standard medium depend on the aim of study. The plates then aerobically incubated at $37^{\circ} \mathrm{C}$ for $18-24$ hours. The pure colonies should be subjected to the primary and secondary biochemical tests for identification as recommended by Barrow and Feltham. ${ }^{43}$

\section{Mastitis pathogenesis}

Once the bacteria invade the teat canal and the mammary glands, mastitis starts. The bacteria start to multiply and release their toxins which will affect the tissue which secretes the milk, leading to increased SCC in the milk and consequently affecting milk's quantity and products, and reducing its quantity. To avoid infection, the udder is protected by teat as the first defense mechanism, because the teat canal contains a sphincter that prevents bacteria from entering and milk from exiting. Also, the canal is covered by keratin from the inside; it is a waxy material that binds pathogens causing mastitis. After milking process is complete, the teat canal could be partially opened for about 1 to 2 hours, giving bacteria existing near the teat opening the chance to enter the canal and cause keratin damage and consequently affecting the mucous membrane which protect the inside of the canal. If bacteria were successful in entering the teat canal, they will face the second defense mechanism which is the mammary gland itself. Once bacteria reach the gland it can multiply and start producing toxins, but the gland will start stimulate the release of inflammatory mediators to attract phagocytes to clear the pathogens. Factors which determine the severity of inflammatory response depend on the host and the pathogen. For the host; the age, immune status, SCC, lactation stage, and parity are all factors that play a role in determining disease severity.

For the pathogen; the species, strain, virulence, and inoculum size, determine the disease severity as well. As the number of leukocytes increases in the milk as a result of inflammatory response, the number of somatic cells increases also. The dead leukocytes, dead mammary epithelial cells, along with clotting factors are secreted in the milk forming aggregations that lead to clots formation. These clots cause duct blockage and prevention of milk removal, and finally cause formation of scars that form small pockets which are difficult to be cured by antibiotics. Practice that increases trauma of the animal's mammary glands include; improper preparation of animal for milk stimulation, excessive milking, use of infected tubes and cannula with mastitis, handling wet teats and not using teat dips, improper usage of udder washes, physical trauma, and injuries of infectious agents and their toxins. Persistence of inflammation cause an internal swelling of the mammary epithelium but it could not be detected by external examination. This inflammation causes damage to gland alveoli that eventually loses shape. When the blood-milk barrier is broken, then components of the extracellular fluid will enter the gland such as; sodium, chloride, hydrogen, potassium, and hydroxide ions. Once these elements enter the gland, they will mix with milk which could also include blood if the damage is severe. At this stage, visible signs could be observed on the udder such as swelling, redness, as well as the milk such as color, $\mathrm{pH}$, water content, and presence of flakes and clots. $^{21,26}$

\section{Prevalence}

Epidemiological data collected during the past two decades shows that clinical mastitis prevalence in Finland during 1995 was 38\%, and during 2001 was $31 \%$, while in Uruguay during 2001 it was $31 \% .{ }^{44}$ camel mastitis prevalence rate was $18.52 \%$, with subclinical mastitis being more common (24.7\%) than clinical mastitis (11.67\%). The main causing pathogens were Staphylococcus for both types of mastitis (41.67\%), then came Streptococcus spp. (21.67\%), Enterobacter spp. $(15.00 \%)$, C. pyogenes $(10.00 \%)$, Micrococcus spp. (5.00\%), Pasteurells spp. (5.00\%) and Pseudomonas aeruginosa $1.66 \%{ }^{45}$ and in Sudan, North Kordofan in 2013, the incidence rate was found to be $25 \%$ when clinically examined but the rate was $13.3 \%$ and $15 \%$ using other techniques such as SCC and WST, respectively. Furthermore, when the milk samples were investigated for mastitis the rate was significantly high $41.66 \%(\mathrm{p}<0.001)$. Pathogens isolated were mainly as follow; Staphylococcus spp. (80.30\%), Bacillus spp. (9.09\%), Pasteurella spp. (6.06\%), Corynebacteria spp. (3.03\%) and Streptococcus spp. $(1.52 \%)$. So, the study indicates that mastitis is predominant in lactating camels with Staphylococcus species being the major cause of it. A study was done in Jordan during 2008 to establish data on camel mastitis and infecting pathogens. The study included about 90 camels from the south providence, and samples were tested using CMT. Clinical symptoms of mastitis were seen in $21 \%$ of the camels, and the main bacterial pathogens were Micrococcus spp., Staphylococcus aureus, Streptococcus spp., and Corynebacterium spp. Isolates were sensitive to the main antibiotics such as gentamycin, ampicillin, and tetracycline. The study concluded that mastitis was actually prevalent in Jordan and mainly of the gram positive cocci. So, efforts must be exerted to improve the health of camels and to establish a program for mastitis infection control. ${ }^{46}$

The prevalence and causes of mastitis differ markedly due to geographical area and individual herd management. ${ }^{47}$ An overall prevalence of camel mastitis was found to be $30.2 \%$ out of which, $4.9 \%$, and $25.3 \%$ were clinical and sub-clinical mastitis, respectively in Jigjiga. ${ }^{24}$ The overall percentage of clinical mastitis was $9.09 \%$ was documented in Sudan. Three forms of clinical mastitis were diagnosed. There was chronic form with high occurrence (72.41\%) followed by acute form $(24.14 \%)$ and the least was the gangrenous form $(3.45 \%)$. The highest occurrence of clinical mastitis was found at the ages between 11-15 years and in late stage of lactation (55\%). The highest incidence of clinical mastitis was found at the first, second and third calving $(65.52 \%)$. The predominant isolated organism was Staphylococcus spp. (37.8\%) followed by E. coli $(18.9 \%)$, Streptococcus spp. (13.5\%), Bacillus spp. (10.8\%), Micrococcus spp. (8.1\%), Corynebacterium spp. (5.4\%) and Salmonella spp. (5.4\%). ${ }^{23}$ The overall prevalence of $(76.0 \%)$ mastitis observed in camel herds examined as assessed by the CMT and clinical examinations of the udder or milk in Eastern Ethiopia (Eyassu and Bekele, 2010). The bacterial species isolated from the camel milk samples include coagulase negative staphylococci $(39.6 \%)$, Streptococcus dysagalactiae (22.2\%), Corynebacteria spp. (9\%), Bacillus spp. (7.6\%), Streptococcus uberis (7.6\%), Escherichia coli (6.3\%), Staphylococcus aureus (4.2\%) and Streptococcus agalactiae (3.5\%).

One hundred and forty-five traditionally kept lactating camels (Camelus dromederius) were examined for mastitis by combination of clinical, mastitis card test and subsequent bacteriological isolation. Clinical and sub-clinical mastitis were prevalent in $8.3 \%(95 \%$ $\mathrm{CI}=4.6,14.4)$ and $20.7 \%(95 \% \mathrm{CI}=14.6,28.4)$ of the studied animals, respectively. This gives an overall mastitis prevalence of $29.0 \%(95 \%$ $\mathrm{CI}=21.9,37.2)$ at animal and $17.9 \%(95 \% \mathrm{CI}=14.9,21.3)$ at quarter levels. High proportion $(33.8 \%)$ of lactating camels had blind teats and $5.5 \%$ had lesions on udder or teat. ${ }^{48}$ 


\section{Treatment of mastitis in camel}

Although some authors have suggested daily intra mammary infusion with antibiotic preparations as used in cattle, there is opposition to this practice because of the particular anatomy of the camelidae udder and because of the difficulty in administering such treatment. ${ }^{49}$ Therapeutic approach in treating acute mastitis is via systemic antibiotics (e.g. trimethoprim-sulfamethoxazole or penicillin/ Aminoglycoside) and anti-inflammatory drugs (flunixin meglumine), with regular stripping of the mammary glands. Hydrotherapy is beneficial in reducing local edema. The teat of the camel udder contains sometimes three separate teat canals that open independently into the teat sphincter. The separate canals drain separate gland complexes. ${ }^{50}$ This implies that for intra mammary treatment of mastitis, not only must each quarter but also each gland complex be treated separately, that is, one intra mammary tube per gland complex. Great caution is necessary when applying intra mammary treatment to camels. The teat canal openings in camel are smaller than those of the cow and thus require smaller canula. Unhygienic and traumatic application of intra mammary treatment is very likely to do more harm than good. Treatment of chronic mastitis is very difficult and the condition often results in the loss of the affected quarter. ${ }^{40,15}$ Intra mammary infections (IMI) with Streptococcus agalactiae (Lancefield type B) in camels are common and have been diagnosed in the United Arab Emirates, ${ }^{19}$ Egypt ${ }^{50}{ }^{\text {Sudan }}{ }^{14,28}$ and Somalia. ${ }^{51}$ In Northern Kenya, Streptococcus agalactiae prevalence of up to $50 \%$ in market oriented camel dairy herds ${ }^{13}$ has become a concern to camel owners. One case of successful parenteral treatment of mastitis in a camel is reported in the literature. ${ }^{22}$ However, published treatment recommendations for mastitis in camels have not been validated..$^{53}$

\section{Prevention and control}

There are three main principles of mastitis control i.e. elimination of existing infection, prevention of new infection and monitoring udder health status. Elimination of existing infections can be achieved by appropriate therapy of the infected cases. Prevention of new infections and monitoring of udder health status can be achieved by proper supplementation of the required nutrients, hygienic measures and essential diagnostic and maintenance procedures. Numerous antimicrobial formulations are available for the treatment of mastitis, but their efficacy alone or in combination with minerals and immunomodulators is not fully established particularly in camels. Elimination through antibiotics has simultaneously increased the resistance problem in diverse bacterial pathogens. Though plant derived products have been used for medicinal purposes for centuries and they possess almost limitless ability to synthesize aromatic substances such as flavanoids (Geissman, 1963). Most are secondary metabolites, of which at least 12,000 have been isolated, a number estimated to be less than $10 \%$ of the total (Schultes, 1978). In many cases, these substances serve as plant defense mechanisms against predation by microorganisms, insects and herbivores. In vitro many laboratories have found thousands of Phytochemicals, which have inhibitory effects on all types of microorganisms. More of these compounds should be subjected to animal and human studies to determine their effectiveness in the whole organisms' system.

Although numerous antimicrobial formulations are available for the treatment of mastitis, but none of them is claimed to be of herbal origin, which could be considered safe, when milk is used after treatment, which leads to drug resistant bacterial strains not only for animals but also for human beings. Moreover, success rate for treatment with the available antimicrobials is not always encouraging. World Health Organization also encourages herbal remedies in global health care program such drugs are easily available at low cost, locally grown and comparatively safe. The principal steps in mastitis control program are to undertake a preliminary mastitis screening survey and to evaluate the udder health status in the herd. ${ }^{54}$ Prevention is always better than treatment, which in case of mastitis it is difficult to completely eliminate it from the animals in the farms, but with careful and continuous control its incidence could be minimized dramatically. The best treatment period is during the non-lactation (dry) phase which proved it cures about $70 \%$ of environmental infection caused by Streptococci. Literature suggest to take the following precautions to ensure proper treatment; complete sanitization of the farmer hands with water and soap, as well as the animal's teat and udder with proper sanitizer, ensure dryness of udder before starting treatment and provide individualized items such as towels for each animal, immerse the teats in a proper teat germicidal solution for at least 30 seconds before removing it with the towel. Then, using alcohol saturated cotton swab clean the teats end, usually if all the four quarters were under treatment, treatment starts with the furthest teat to the closest to avoid contamination between treated and not. If antibiotics are being administered, then treatment starts from the closest teats to the furthest to prevent clean ends contamination. Finally, after treatment has completed teats must be immersed again in effective germicidal teat solutions. ${ }^{21}$

The main idea behind mastitis control is to manage it through limiting pathogen exposure to animal's teat, or increase infection resistance among the dairy animals. The following procedures must be carried out to ensure disease control. First; proper sanitation and husbandry performance, second; mastitis treatment during the nonlactation period, third; teat dipping post milking and forth; chronically infected animals must be removal, fifth; continuous monitoring of SCC and mastitis and immediate treatment. ${ }^{21}$ In some countries such as Ethiopia, herbal medicine is still used as preventive and curative traditional medicine for both humans and animals alike. ${ }^{55}$ Actually, $80 \%$ of humans refer to traditional than medical medicine, and it is used for more than $90 \%$ of animals. So, it was also used as a treatment for mastitis in Ethiopia, but although their essential role in both curing and maintaining health of humans and animals, it is at danger of permanent loss. This is due to $f$ the inappropriate passage of information from generation to the next through verbal rather than writing method, other factors for loss also include changes in the environment, agriculture, and urbanization. Documentation of use of these herbal medicines are being done but not in the field of veterinary, but data showed the importance of certain herbal plants as medicine and this study aims to examine them for mastitis.

Nine plant species were examined in a study during a two years' period (2007-2009) done in the Tigray region of Ethiopia. All plant species used showed antibacterial activity except one plant $S$. hastifolium, and out of the remaining 11 plant, 5 showed promising antibacterial activities. So, the study concluded that the antibacterial activity of plants validates its use by the people as a herbal medicine against mastitis and other diseases, and that they require further assessment to characterize them and identify their appropriate dosage for use $^{56}$ The important points to keep in mind while controlling mastitis is that prevention is number one procedure though ensuring dry teats, presence of liner slips between teat as much as possible, teat dip in effective germicidal solution, and always observing the milking procedure..$^{77}$ Contagious mastitis pathogens such as Staphylococcus aureus which stands as the major causing agent is difficult to treat and during the lactation period successful is very small and the animal might be removed from the herd. While, Streptococcus agalactiae could be cured more successfully with antibiotics and with good 
management procedures mastitis could be eliminated completely. Another type, Strepotcoccus dysgalactiae which could be found everywhere in the farm itself or the animal, their prevention could be accomplished by following the proper sanitation procedures and antibiotics protocol. ${ }^{21}$ Steps used to reduce the level of SCC and control mastitis include; teat dipping, treat during dry period, accurate milking procedure and system, always clean and dry environment, chronically ill animals must be removed, and apply SCC monitoring program. To ensure elimination of the disease, animal's quarters must be treated during dry off phase with appropriately designed antibiotics. Additionally, infected animals must be removed and isolated away from others to prevent cross-infection. ${ }^{57}$

\section{Economic importance of camel mastitis}

In terms of economic loss, mastitis is undoubtedly the most important disease with which the dairy industry has to contend. This loss, as in dairy animal, is occasioned much less by fatalities, although fatal cases do occur, than from the reduction in milk production from affected quarters. The clinical syndrome may vary from per-acute inflammation with toxemia to a fibrosis which develops in chronic mastitis until most of the secretary tissue has been destroyed. There is the additional danger that the bacterial contamination of milk from affected camels may render it unsuitable for human consumption or interfere with manufacturing process or in rare cases, provide a medium of spread of diseases to humans. Streptococcal sore throat and brucellosis may be spread this way, through drinking unpasteurized milk. ${ }^{16}$ Treatment of chronic mastitis is very difficult and the condition often results in loss of the affected quarter. ${ }^{40,15}$ Subclinical mastitis is a major factor in depressing milk yield and has a much greater impact on the productivity of lactating animals than the sporadic clinical forms of the disease. Chronic inflammatory infection ultimately leads to loss of intact quarter by destruction of the gland tissue. Loss of teat is reported from one third of Gabra and Somali camels in Northern Kenya. ${ }^{13}$ Mastitis effects on the dairy industry include; Loss in the animal ability to produce milk either temporary or permanent, the milk quality is reduced with less favorable characteristics, reduction in milk price due to high SCC presence, milk loss because of antibiotic treatment, and veterinary care costs, labor costs increase, laboratory testing cost to control the milk quality and animal status, reduced productive life of the animal, less meat value of the animal after slaughter, annual losses due to reduce overall production of dairy product for the needs of the country. ${ }^{26,58-63}$

\section{Conclusion and recommendations}

In conclusion, Camel mastitis has been reported from nearly all camel rearing countries. Many infective agents have been implicated as causes of mastitis in camels, however, bacterial infections are considered as the primary cause of mastitis in camel. Transmission mechanisms depend on the bulk of the infection in the environment, including: infected quarters; efficiency of milking personnel; susceptibility of the camel, which is related to the stage of lactation, age of the camel and level of inherited resistance. Subclinical mastitis is more prevalent than other form of mastitis, and unfortunately the affected animal could affect other animals because it acts as microorganism reservoir. Diagnosis of mastitis can be done through clinical examination, $\mathrm{pH}$ test, California Mastitis test, Somatic Cell Count, and bacteriological analyses for confirmation may be made by culturing. The prevalence of mastitis differs markedly due to geographical area and individual herd management. For instance, an overall prevalence of camel mastitis was found to be $30.2 \%$ and $76 \%$ in Eastern Ethiopia. Therapeutic approach in treating acute mastitis is via systemic antibiotics and anti-inflammatory drugs, with regular stripping of the mammary glands. Treatment of chronic mastitis is very difficult and the condition often results in the loss of the affected quarter. There are three main principles of mastitis control methods, such as elimination of existing infection, prevention of new infection and monitoring udder health status. Economic importance of mastitis includes: loss of milk production and quality with less favorable features, reduction in milk price due to high SCC presence, milk loss because of antibiotic treatment, and veterinary care costs. ${ }^{64-66}$

Therefore, based on this conclusion the following recommendations are forwarded:

1) Targeting prevention and control effort is needed through early diagnosis, treatment and by avoiding possible risk factors

2) Maintenance of milking hygiene by milking healthy animals first and infected later

3) Regular removal of dung for maintaining bedding hygiene

4) Milking animals shall be kept away from flies and insects

5) Selection of antibiotic should be done by in vitro chemotherapeutic sensitivity testing

6) Animals from milking shall never be abruptly dried at once rather animals shall be dried slowly by reducing the frequency of milking.

\section{Acknowledgments}

None.

\section{Conflicts of interest}

The authors declare there is no conflict of interests.

\section{Funding}

None.

\section{References}

1. Abdella ME, Mohammed GE. Clinical study on camel mastitis (Camelus dromedarius) at Butana Region, Sudan. SUST Journal of Agricultural and Veterinary Sciences (SJAVS). 2014;15(2).

2. Abdi $\mathrm{H}$, Berihu $\mathrm{H}$, Addisalem $\mathrm{H}$, et al. Prevalence of camel mastitis in Jijiga Town, Ethiopia. Afr J Agric Res. 2013;8(24):3113-3120.

3. Abdurahman OA Sh, Agab H, Abbas B, et al. Relations between udder infection and somatic cells in camel (Camelus dromedarius) milk. Acta Vet Scand. 1995;36(4):423-431.

4. Abdurahman OA Sh. Detection of subclinical mastitis in camels:relationship between udder infection and inflammatory indicators in milk. In: Bonnet P, editor. Dromadaires et chameaux, animaux laitiers/Dromedaries and camels, milking animals. Actes du colloque. 1998.

5. Abdurahman OA Sh. Udder health and milk quality among camels in the Errer valley of eastern Ethiopia. Livestock Research for Rural Development. 2006;18:3-11.

6. Abdurahman O Sh, Cooray R, Bornstein S. The ultra structure of cells and cell fragments in mammary secretions of camelus bactrianus. $J$ Vet med A. 1992;39:648-655.

7. Abdurahman OA-Sh, Younan M. The udder health, In:Farah and Fisher (Edt.), Milk and meat from the camel handbook on product and processing vdfhochschulerleg AG and der ETH Zurich. 2004:73-76. 
8. Abera M, Abdi O, Abunna F, et al. Udder health problems and major bacterial causes of camel mastitis in Jijiga, Eastern Ethiopia:implication for impacting food security. Trop Anim Health Prod. 2010;42(3)341347.

9. Alamin MA, Alqurashi AM, Elsheikh AS, et al. Mastitis incidence and bacterial causative agents isolated from lactating she-camel (Camelus dromedarius). Journal of Agriculture and Veterinary Science. 2013;2(3):7-10

10. Al-Ani FK, Al-Shareefi MR. Studies on mastitis in lactating onehumped camels (Camelus dromedarius) in Iraq. J Camel Pract Res. 1997;4:47-49.

11. Alhendi AA. Common diseases of camels (camelus dromedarius) in eastern province of Saudi Arabia. Pakistan Vet J. 2000;20:97-99.

12. Al-Juboori A, Kamat N, Sindhu J. Prevalence of some mastitis cause in dromedary camels in Abu Dhabi, United Arab Emirates. Iraqi J vet Sci. 2013;27:9-14.

13. Al-Majali A, Bani IZ, Al-Hami Y, et al. Lactoferrin concentration in milk from camels (camelus dromedarius) with and without subclinical mastitis. Intern J Appl Res Vet Med. 2007;5(3):120-124.

14. Al-Majali AM, Al-Qudah KM, Al-Tarazi YH, et al. Risk factors associated with camel brucellosis in Jordan. Trop. Anim. Health Prod. 2008;40(3):193-200.

15. Almaw G, Molla B. Prevalence and etiology of mastitis in camels. (Camelus dromedaries) in Eastern Ethiopia. J Camel Pract Res. 2000; 7:97-100

16. Al-Otaibi, El-Demerdash. Nutritive value and characterization properties of fermented camel milk fortified with some date palm products chemical, bacteriological and sensory properties. International Journal of Nutrition and Food Sciences. 2013;2(4):174-180.

17. Al-Ruwaili MA, Khali OM, Selim SA. Viral and bacterial infections associated with camel (Camelus dromedarius) calf diarrhea in North Province, Saudi Arabia. Saudi J Biol Sci. 2012;19(1):35-41.

18. Al-Tofaily YI Kh, Alrodhan MAN. Study on clinical mastitis (Bacteriological) in she-camels (Camelus dromedaries) in some areas of middle Euphrates in Iraq. AL-Qadisiya Journal of Vet Med Sci. 2011;10(2):66-76.

19. Amel MA. Bacteria and fungi isolated from she-camel mastitis in the Red Sea Area of the Sudan. Thesis MSc, Sudan, Africa: University of Khartoum; 2003.

20. Barbour EK, Nabbut NH, Frerichs WM, et al. Mastitis in Camelus dromedarius in Saudi Arabia. Trop Anim Hlth Prod. 1985;17(3):173179.

21. Barłowska J, Szwajkowska M, Litwi'nczuk Z, et al. Nutritional value and technological suitability of milk from various animal species used for dairy Production 2011;10(6):291-302.

22. Barrow GI, Feltham RKA. Cowan and Steel's Manual for Identification of Medical Bacteria 3rd. United Kingdom: Cambridge University Press; 2003.

23. Blood DC, Radostits OM. Veterinary medicine. A Textbook of disease of cattle, sheep, pigs, Goats and Horses. 10th edn. Baillion Tindall; 2007:501-559.

24. Bramley AJ. The effect of subclinical Staphylococcus epidermidis infection of the lactating udder on its susceptibility to infection with Streptococcus agalactiae or Escherichia coli. Br Vet Journal. 1978;134(2):146-151.

25. Eisa M, Mustafa A. Production systems and dairy production of Sudan camel (camelus dromedarius):A review. Middle-East journal of scientific research. 2011;7(2):132-135.
26. Eyassu S, Bekele T. Prevalence and etiology of mastitis in traditionally managed camels (Camelus dromedarius) in selected pastoral areas in eastern Ethiopia. Ethiop Vet Journal. 2010;14(2):103-113.

27. Fadlelmula A, Al-Dughaym A, Mohamed G, et al. Bovine mastitis:epidemiological, clinical and etiological study in a Saudi Arabian large dairy farm. Bulgarian journal of veterinary medicine. 2009;12(3):199-206.

28. Faye B. Guide de lelevage du dromedaire, leve edn. Libourne France. Sanofi jante nutrition animal Production. 1997;119:115-117.

29. Fazlani SA, Khan SA, Farazl S, et al. Antimicrobial susceptibility of bacterial species indentified from mastitic milk samples of camel. $J$ African Biotech. 2011;10(15):2959-2964.

30. Fischer A, Liljander A, Kaspar H, et al. Camel Streptococcus agalactiae populations are associated with specific disease complexes and acquired the tetracycline resistance gene tetM via a Tn916-like element. Vet Res. $2013 ; 44: 86$

31. Guidry AJ. Mastitis and the immune system of the mammary gland. In:Larson BL (Edt.), Lactation. Iowa, USA: The Iowa State University Press; 1985:229-262.

32. Hawari A, Hassawi D. Mastitis in one humped she-camel (camelus dromedarius) in Jordan. J bio Sci. 2008;8:958-961.

33. Hegazy AA, El-Dughaym A, Alaknah M, et al. Studies on mastitis in female camel with special reference to brucellosis. J Camel Sci. 2004;1:96-102.

34. Honkanen-Buzalski T, Pyörälä S. Monitoring and management of udder health at the farm. In:Sandholm M, Honkanen-Buzalski T, et al. (Eds.), The bovine udder and mastitis. Finland: University of Helsinki; 1995:252-260.

35. Iyer AP, Albaik M, Baghallab I. Mastitis in camels in African and Middle East Countries. J Bacteriol Parasitol. 2014;5:188.

36. Kalayou S, Haileselassie M, Gebre-egziabher G, et al. In-virtro antimicrobial activity screening of some ethnoveterinary medicinal plants traditionally used against mastitis, wound and gastrointestinal tract complication in Tigray Region, Ethiopia. Asian Pac J Trop Biomed. 2012;2(7):512-522.

37. Kalla DJU, Butswat ISR, Mbap ST, et al. Microbiological examination of camel (Camelus dromedarius) milk and sensitivity of milk microflora to commonly-available antibiotic in Kano, Nigeria. Sav J Agric. 2008;3:1-8.

38. Kapur MP, Khanna BM, Zing RP. A peracute case of mastitis in a shecamel associated with Klebsiella pneumonia and Escherichia coli. Indian Vet Journal. 1982'59:650-651.

39. Karamy SA. Bacteriological studies on mastitis in small ruminants and she- camels in Upper Egypt. J Egypt Vet Med Assoc. 1990;50:67-79.

40. Khan M, Khan A. Basic facts of mastitis in dairy animals:A review. Pakistan veterinary journal. 2006;26(4):204-208.

41. Korhonen H, Kaartinen L. Changes in the composition of milk induced by mastits. In: Sandholm, M, Honkanen-Buzalski T, Kaartinen L, editors. The bovine udder and mastitis. Finland: University of Helsinki; 1995:76-82.

42. NMC. Laboratory and field handbook on bovine mastitis:National Mastitis Council (NMC) Inc, Madison; 1997.

43. Obied AI, Bagadim HO, Muctar MM. Mastis in camelus dromedaries and somatic cell content of camel milk. Res Vet Sci. 1996;61:55-58.

44. Quandil SS, Qudar J. Bacteriological study of a few mammitis cases on she-camel (camelus dromedarius) in United Arab Emirates (preliminary note). Rev Med Vet. 1984;135:705-707. 
45. Quinn PJ, Carter ME, Markey B, et al. Clinical veterinary microbiology. London, England: Wolf publishing; 1999. 327 p.

46. Radostits OM, Gay CC, Blood DC, et al. Veterinary Medicine:A Textbook of the Diseases of Cattle, Sheep, Pigs, Goats and Horses, 9th edition Philadelphia. WB Saunders; 200:563-613.

47. Regassa A, Golicha G, Tesfaye D, et al. Prevalence, risk factors, and major bacterial causes of camel mastitis in Borana Zone, Oromia Regional State, Ethiopia. Trop Anim Health Prod. 2013;45(7):15891595 .

48. Saad NH, Thabet AER. Bacteriological quality of camel milk with special reference to mastitis. Assist. Vet. Med (1993). Procedures for mastitis diagnosis and control. Vet Cin North Am Food Anim Journal. 1993;28:194-199.

49. Salah SK, Faye B. Detection of subclinical mastitis in dromedary camels (Camelus dromedarius) using somatic cell counts, California mastitis test and udder pathogen. Emir J Food Agric. 2011;23(1):48-58.

50. Sanaa OY. Bacterial diseases of the reproductive system of camels (Camelus dromedarius) in Eastern Sudan. Journal of Animal and Veterinary advance. 2005;4(7):642-644.

51. Schalm OW, Carall EJ, Jain NC. Bovine mastitis. Philadelphia PA, USA: Lea and Fahiger; 1971;24:128.

52. Schroeder J. Bovine Mastitis and milking management. US: North Dakota State University; 2012.

53. Shearer J, Harris JB. Mastitis in dairy goats. IFAS extension, USA: University of Florida; 2003.

54. Smut MMS, Bezuidenhout AJ. Anatomy of the dromedary. Oxford, USA, Clarendon Press; 1987. 230 p.

55. Suheir IA. Some bacterial species, mycoplasma and fungal isolates associated with camel mastitis. MV Sc. Thesis, Sudan: University of Khartoum; 2004.

56. Teka T. The dromedary in Eastern Africa countries. Nomad People. $1991 ; 29: 31-41$
57. Tibary A, Anouassi. Lactation and udder diseases. In: Skidmored, Adams GP, editors. Recent advances in camelid reproduction, Ithaca, New York: International Veterinary Information Service; 2000.

58. Tuteja FC, Dixit SK, Patil NV, et al. Camel mastitis. a technical bulletin, NRCC - 2013/1. 2013.

59. Viguier C, Arora S, Gilmartin N, et al. Mastitis detection:current trends and future perspectives. Trends Biotechnol. 2009;27(8) 486-493.

60. Wanjohi GM. Occurrence of Subclinical Mastitis, Brucellosis and Factors Responsible for Camel Milk Contamination in Garissa and Wajir Districts of North-Eastern Kenya. BVM Thesis, Africa: University of Nairobi; 2014

61. Woubit S, Bayleyegn M, Bonnet P, et al. Camel (Camelus dromedarius) Mastitis in Borena Lowland Pastoral Area, Southwestern Ethiopia. Revue Élev Méd vét Pays trop. 2001;54(3-4):207-212.

62. Younan M, Aliz B, Muller W. Application of the California mastitis test in intrammary Streptococcus agalactiae and Staphylococcus aureus infection of camels (camelus dromedarius) in Kenya. Prev vet Med. 2001;51(3-4):307-316.

63. Younan M, Fink K, Laemmler C, et al. Streptococcus agalactiae in marketed camel milk. In:Livestock Community and Environment Proc. 10th Int. conf. Association of Institutions of Tropical Veterinary Medicine, Copenhagen, Denmark. Europe: The Royal Veterinary and Agricultural University; 2002. 555 p.

64. Youssef SAH. The use of antibiotics in camels. In: Allen WR, Higgins AJ, Mayhew IG, editors. Proc. 1st Int. camel conf., Dubai, United Arab Emirates 2-6 February 1992. Newmarket, Suffolk, UK R and W; 1992:383-387.

65. Therapeutic approach in treating acute mastitis is via systemic antibiotics and anti-inflammatory drugs, with regular stripping of the mammary glands.

66. Osman KM1, Samir A, Orabi A, et al. Confirmed low prevalence of Listeria mastitis in she-camel milk delivers safe, alternative milk for human consumption. Acta Tropica. 2014;130:1-6. 